\title{
Application of Bandura's Social Learning Theory in the Moral Education of Secondary Vocational College Students
}

\author{
Rui Wang* \\ Department of Basic Education, Henan Chemical Technician College, Kaifeng 475000, Henan Province, China \\ *Corresponding author: Rui Wang, wangrui20210704@163.com
}

\begin{abstract}
In recent years, with the high rate of juvenile delinquency, people pay more attention to the moral education of students in secondary vocational colleges. Based on the framework of social learning theory, this paper explores the systematic and comprehensive application of social learning theory in the moral education course. From the cognition of the behavior to the selection and internalization of the representation of the model behavior, and finally the selective externalization of the representation symbol to generate the behavior, the influencing factors and their utility in each stage of the production of moral behavior are analyzed step by step, assisting students to establish correct outlook on life and values, and cultivating their "key abilities." When students face a complex and diverse social environment, they can make judgments in line with the general moral standards of the society, and then seek to improve the effectiveness of the moral standards of secondary vocational students, and strive to maximize the effectiveness of moral education.
\end{abstract}

Keywords: Social learning theory; Secondary vocational college student; Moral education

Publication date: August 2021; Online publication: August 30, 2021

\section{Introduction}

At present, juvenile delinquency incidence is emerging one after another, and school violence is also on the rise. Thus, the implementation of moral education for secondary vocational college students is imminent. Moral education is not only maxims in the books and assessed through test papers, but also, more importantly, a series of lessons that encourage secondary vocational students to accept the correct moral education and transforms the internal cognition into the correct behavior motivation. Since most students are adolescent and have outstanding character characteristics, it is difficult to teach moral education to this particular group. Therefore, in order to complete the goal of moral education, it is not enough to start from the students themselves. Education workers should develop a set of complete and systematic theories, including social learning, moral awareness, self-reflection and other aspects that are suitable for the development of secondary vocational students to cultivate their moral awareness and promote the perfection of moral education.

Bandura's social learning theory consists of four aspects: ternary interactive determination theory, observational learning theory, self-regulation theory, and self-efficacy theory. The social learning theory and the implementation of moral education work have a good adhesion. First of all, Bandura believes that in the process of social learning, individuals, as cognitive subjects, interact with their behaviors and the environment where they live in. In the interpretation of individual behaviors, not only internal factors should be considered, but also environmental factors should be analyzed. Internal factors are dominant, followed by environmental factors. Secondly, while conducting "hands-on learning," Bandura emphasizes 
the importance of observational learning (indirect learning), and divides the process of observational learning into four stages: paying attention to learning behavior, keeping an impression in mind, generating self-awareness through self-consciousness regulation, and forming motivation to produce external behavior. The purpose of moral education is a process from external guidance to individual internal reinforcement which is finally reflected in external performance. However, social learning theory is inseparable in the application of moral education for secondary vocational students, necessitating a discussion, so as to increase the effectiveness of the implementation of moral education.

\section{A brief description of bandura's social learning theory}

\subsection{Triadic reciprocal determinism theory}

Bandura believes that the factors influencing individual behavior are complex, and unlike traditional behaviorist environmental determinism, the relationship among individual cognition, environment and behavior should be mutual, with a dynamic relationship between the two determining each other ${ }^{[1]}$. The triadic interaction determinism emphasizes that person, environment and behavior are influencing one another, and this influence is not static; their mutual influence will change with the change of the situation and individual activities. For example, when people are in the library and everyone is talking in a low voice, people naturally talk in a low voice as well. At this time, although the subject is also conscious, the environment plays a greater role. The "triadic interaction determinism" focuses on the study of individual psychological activity and daily behavioral performance from the dynamic interaction between the individual, the environment and behavior, treating individual psychological activity as an interactive system between the individual, the environment and behavior, grasping the relationship between the individual and the environment, which is theoretically more rational, and the three elements form an inseparable whole ${ }^{[2]}$.

\subsection{Learning from observation theory}

The most important learning method in Bandura's social learning theory is the observation learning theory. Observational learning is an indirect method of learning by observing the behavior of role models (mainly individuals with whom the individual identifies) and consciously internalizing their own behavior. This learning method is faster for knowledge and ability acquisition behavior than direct learning. Bandura argues that this is not an indirect traditional learning approach, but more relatable to the presence of various alternative reinforcement in influencing individual behavior. This is one of the main differences between Bandura's social learning theory and traditional behaviorism.

In observational learning, there are four main components, namely attention, retention, generation, and motivation. The explanation of each of these processes are as follows:

(1) The process of attention. People are exposed to the kind of role models they observe in whatever environment they are in, and they acquire the learning information they pay attention to by making precise perceptions based on their individual need.

(2) The process of retention. In order to achieve the fundamental purpose of "learning," individuals should consciously keep the observed behavior in mind.

(3) The process of generation. The transformation of the words and representations produced by the retention process into behaviors is the generative process. In this process, reinforcement will exert a strong influence on the externalization of behavior.

(4) The process of motivation. If individuals perceive value in the presence of certain behaviors, they will actively display the learned behaviors. Otherwise, they will not. 


\subsection{Self-regulation theory}

Self-regulation mechanism is the experience of a higher level of individual internalization behavior. As individuals begin to learn ethical behavior, they are subject to external reward or punishment mechanisms, and as they grow internally, they need to develop complete self-regulatory mechanisms to internalize their own ethical behavior without external rewards.

\subsection{Self-efficacy theory}

Bandura explained the sense of self-efficacy as "an individual's belief in his ability to organize and execute to achieve a specific achievement" in his book Self-efficacy: The Implementation of Control ${ }^{[3]}$. To put it simply, self-efficacy refers to the individual's feelings of self-assurance and self-confidence when facing a certain task. Bandura points out that there are four sources of self-efficacy, i.e., successful experience, alternative experience, social persuasion, and physical and mental state.

Secondary school students are in the stage of adolescence. During this period, the secondary vocational students are not mature, so they lack the rational cognition, and are socially vulnerable to adverse external environment influence. Bandura's social learning theory has very important practical significance and helps solve the development problem of secondary vocational student.

\section{Moral question of secondary vocational student in our country}

The emergence of a problem can often be viewed from both internal and external causes. The moral education problem of secondary vocational students can be analyzed from the aspects of students themselves and their family as well as school and social environment they live in. Bandura's social learning theory shows that the relationship between human, behavior and environment is mutually determined. The individual is the dominant factor in behavior, and the environment is a secondary factor in behavior, and these two factors are equally influencing the production of behavior. In terms of the cultivation of moral behavior of secondary vocational students, the cultivation method is moral education, the implementers are teachers and parents, and the implementation environment is the society. Problem in any of these aspects will affect the acquisition and manifestation of moral behavior of secondary vocational students.

\subsection{Inadequacy of moral understanding among secondary vocational students}

\subsubsection{Lacking thoroughness in the understanding of morality}

The process of moral education begins with cognition and ends with the formation of moral behavior. Moral cognition is the foundation of the formation of moral behavior ${ }^{[4]}$. For the students, most of their moral cognition comes from school education, which is taught by full-time teachers in accordance with the requirements and objectives of the syllabus.

However, teachers always indoctrinate students with theoretical and conclusive morality, but rarely explain why the behavior is moral. It is difficult for rebellious teenagers to truly accept the half-understood moral education knowledge from the bottom of their hearts; they may resist the moral education and act against morality, thinking that the so-called "moral outlook" is hypocritical.

\subsubsection{An unconventional view of role models}

Generally speaking, in the process of observation, people believe that the model demonstration is consistent with their own cognition, and when it generates recognition or resonance, the model behavior will be transformed into symbolic representation and stored in the brain of the observer waiting for the second transformation ${ }^{[5]}$. In the selection of observation targets, students often act according to their own preferences rather than moral standards, and they are more inclined to be "unconventional," thinking that strange clothes is the manifestation of personality. Furthermore, worshipping street bullies, tattoos, cursing, 
money, puppy love, and even sexual openness are some of the problems of the secondary vocational stage. An advance in network also allow students to come into contact with more information, such as "Kuai Shou" and "Dou Yin." The lack of moral cognition causes loss of judgment of social behavior, which in turn causes campus violence, disruption of public order, drug misuse, injuries and death in recent years.

\subsubsection{The delayed reinforcement of good moral behavior}

For minors, the functional value of a certain behavior is to be recognized and to obtain higher self-efficacy. For example, some people think there is no need to give up a seat on the bus to those in need because they lack moral judgment. While some people find that giving up their seat is not appreciated or noticed, and that not giving up their seat will not be condemned or punished. Two entirely different actions get the same result. At this time, the self-regulation mechanism does not play a role and the sense of self-efficacy does not increase. Therefore, moral behavior does not get externalized because of the lack of an internal drive.

\subsection{Moral education environment of secondary vocational students}

\subsubsection{Lack of corresponding attention to moral education in schools}

School education is the main path of moral education for secondary vocational students. Moral education, as an independent subject, has corresponding syllabus and teaching materials, just like Chinese, mathematics, foreign languages and other general subjects would have. However, it is not simply theoretical indoctrination. On the contrary, moral education is the education with the closest connection with reality among all subjects. In the teaching process, the moral education course is only a public course in the school, and the choice of moral education textbooks for secondary vocational students is less. Whether the depth of the content of the textbooks is suitable for the psychological development level of secondary vocational students is also what most secondary vocational colleges need to carefully choose.

\subsubsection{Deviation of parental guidance in family education}

Parents play the role of "teacher" in family education. Specifically, they guide and demonstrate. However, due to the influence of various factors such as education level and self-moral awareness, many parents do not realize that the role they play in family education, leading to a negative impact on the cultivation of moral behavior of secondary vocational students. For example, when a child disturbs others in a public place, the parents, instead of stopping it, think it is the child's natural active nature, thus reinforcing their originally wrong behavior. Another example is the children will imitate their parents if they commit littering; when the parents yell at the waiter, the children will never learn how to respect others. This kind of "acquiescence" education will do great harm to the formation of moral concept of secondary vocational students. Moreover, students' behavior largely stems from the parents' shallow moral awareness and lack of the moral behavior.

\subsubsection{The lack of "positive energy" in society}

According to Bandura's social learning theory, motivation is the catalyst for theory to be transformed into behavior. People are influenced by external stimuli when they externalize moral behaviors. In recent years, we have seen that there have been many incidents that violate public moral awareness, and the most prominent of which is the incident of helping or not helping people. When faced with an elderly person who falls, adults still make difficult choices. Many cases show that the person who helps may be framed as the culprit who knocked down the old man, and he/she will also have to pay the medical bills, and even face the criticism of public. The impact of these cases on adults is not clear, let alone the secondary vocational students whose physical and mental development is not perfect. If these social "negative energy" becomes the main model in the social observational learning of secondary vocational students, the students 
may consider helping the elderly who fell will end up with more troubles, and this ultimately prevents the creation of correct moral behavior.

\section{Application of social learning theory in moral education of secondary vocational students 4.1. Emphasizing the self-construction of the internal moral standards of secondary vocational students}

Both parents and teachers need to understand that the implementation of moral education is not limited to unilateral learning in school or at home. In any circumstances, learning by example will resonate with secondary vocational students. Bandura believes that example demonstration plays an extremely important role in the formation and development of individual morality. It is not only the universal source of moral cognition and moral behavior, but also can affect and change the development of moral reasoning. It also has the function of substitution and reinforcement to stimulate their moral behavior ${ }^{[6]}$.

In the traditional teaching mode, teachers are the leading ones usually. Teachers directly inculcate the established knowledge to students. As a result, students passively accept knowledge and fail to experience the pleasure of exploring knowledge. If the theoretical learning only depends on the lessons in the classroom, and it is not combined with practice in life, then the knowledge students have learned can be easily forgotten. Moral education is a course education that is imperceptible to individual thoughts and cognition. When teachers conduct moral education, they should change the teaching methods to be more conducive to students' acceptance and learning of knowledge, such as "integrated teaching." The so-called "integrated teaching" simply means that in professional course, teachers focus on the development of practical skills and establish several modules to combine theory and practice to promote the overall development of students ${ }^{[7]}$. Teachers assign tasks to students in class, and students study modules in groups so as to explore knowledge independently. For example, if students want to learn how to repair cars, they need to learn the knowledge of car structure, where each part is and how to repair it if there is a problem; this is how the students learn to repair cars by understanding the car parts and structure. However, "integrated teaching" of moral education is not as practical and efficient to yield good results in students as that of professional course.

Therefore, educators should emulate the noble character for demonstration, offering a clear and stable moral evaluation standard, and encourage the secondary vocational students to develop correct judgments through the various activities. We can create various scenarios to secondary vocational experience as much as possible. In the daily teaching work, teacher can design more behavior guide teaching activities, so that students can learn through activities. It enables secondary vocational students to constantly consolidate correct moral concepts and internalize moral standards in observational learning so that they can improve the level of self-regulation and conduct self-education consciously [8].

\subsection{Cultivation of students' critical thinking ability through observational learning}

Students in secondary vocational schools spend most of their time learning theoretical knowledge and practical operation of their own major. But the moral education curriculum is more of a theoretical explanation. This requires moral teachers to pay attention to the cultivation of students' ability of observation and learning in the daily teaching process, including the concentration of attention, endurance training and other abilities. Teachers can allow students to go through a series of activities, such as attention and maintenance, so as to imperceptibly strengthen their consciousness When students behave well, teachers praise or give reward to strengthen the excellent behavior of students.

In teaching, moral teachers should pay attention to the cultivation of students' critical thinking ability. Let the students discuss and analyze the cases which teacher collects from life and examples from around the students. Regardless of whether the guidance of the case is positive or negative, students deepen their 
impression of the case through careful observation and classroom discussion. On the one hand, it deepens the impression of students on the case; on the other hand, through the exchanges between teachers and students, the discussion helps foster students critical thinking ability. This not only exercises the language expression skills of secondary school students, but also enriches their concepts through the exchanges of ideas among themselves. Teachers are able to provide more targeted coaching by using the correct values in classroom summaries ${ }^{[9]}$.

\subsection{Improving the level of students' self-efficacy and enhancing learning confidence}

Learning ability and understanding ability of students who are in the secondary vocational colleges are generally weak. They are inclined to either not want to learn or have difficult to learn. Students have different educational backgrounds. When secondary vocational students can't get a sense of accomplishment in learning, their self-efficacy level cannot be increased and they lack motivation to learn. To solve such a problem, moral education teachers need to test students' self-efficacy levels in teaching and thus carry out stratified teaching, which require setting different teaching goals according to students' different knowledge levels. Teachers design teaching sessions differently, provide targeted instruction to different students, and assign tasks of appropriate difficulty to students of different levels. Teachers should consciously create opportunities for students to succeed and to experience the pleasure of success in time by accomplishing small goals, which ultimately have the potential to increase students' self-efficacy and develop learning confidence ${ }^{[10]}$.

\subsection{Maximizing the transmission function of the positive energy of the network}

Nowadays, with the rapid development of science and technology, the Internet is an indispensable place for secondary vocational students' learning and entertainment. The rich content and fast speed of network communication have overcome the limitations of monotonous and boring traditional ideological and moral education, creating a lively new educational environment for the formation of secondary vocational students' ideological and moral character. In daily teaching work, teachers can use the convenience of the network to discuss hot social issues with students and increase students' perception of the society. At the same time, teachers can impart the current popular and correct moral concepts to students. Nevertheless, the Internet also contains a large amount of unhealthy information. This unhealthy information seriously corrodes the mind of secondary vocational students, negatively and profoundly affecting the formation of secondary vocational students' ideology and moral character. Moreover, most of the self-study time of secondary vocational students is used for network browsing and online games. In the face of the complex network world, they need a pure network environment to shape the inner role model. Therefore, China should regulate the network and standardize the network civilization vigorously through the law, administrative, economic and other means, making full use of the network to promote the physical and mental health of secondary vocational students so that they will get the correct moral view from the erosion of the concept of injustice.

\section{Conclusion}

To sum up, the development of social learning theory has important theoretical and practical significance for the development of moral education of secondary vocational students. Regardless of the type of education thought, we should prevent the stagnation of stereotypes, and advocate the interactive determinism of the relationship between individual, behavior and environment. The moral value of Bandura's social learning theory focuses on the fact that observational learning is conducive to the formation of good moral behavior habits and enhancement of self-efficacy. It is helpful for secondary vocational students to engage in moral practice consciously, and for moral teachers in teaching students in 
accordance with their aptitude in the classroom, so as to promote individual moral progress. If we can use social learning theory scientifically, it has important practical value to strengthen the moral construction of citizens and improve the moral level of citizens in the entire society. To be specific, teachers should control certain conditions and methods in their daily teaching; providing good examples and rewarding good behavior helps students' character formation and development, and could inspire modern moral education construction as well as education and teaching reform in China.

\section{Disclosure statement}

The author declares that there is no conflict of interest.

\section{References}

[1] Bandura A, 2001, Social Foundations of Thought and Action: Social Cognitive Theory (I). East China Normal University Press, (11): 5-30.

[2] Zhang X, 2015, The Application of Bandura's Social Learning Theory in Adolescent Moral Education. Loudoun University, 7-8.

[3] Huang W, Han F, 2008, Bandura's Process Theory of Observational Learning and Its Application to Model Education. Journal of Higher Correspondence Education (Philosophy and Social Sciences), (11): $51-78$.

[4] Luo X, 2008, A Study of Self-efficacy of Junior Middle School Students in Ideological and Moral Courses. Hangzhou Normal University, (6):14-5.

[5] Shen L, 2011, On the Moral Development View of Bandura's Social Learning Theory. Education Exploration, (1): 67-8.

[6] He S, 2012, Bandura's Theory of Social Learning Moral Education and Its Implications. New West, (14): $160-1$.

[7] Cheng D, 2015, Innovation of "Teaching-Doing Integration" Teaching Modern Higher Vocational Ideological and Political Courses. Journal of Teaching and Management, (02)36:36-39.

[8] Xu H, Wu G, 2015, The Moral Value Exploration of Bandura's Social Learning Theory. Peoples Tribune, (02): 208-10.

[9] Ruan X, 2013, On the Cultivation of Students' Critical Thinking Ability. Journal of Reading and Writing, 10(01): 56-7.

[10] Wang J, Li Y, 2014, On the Improvement of Self-efficacy of Secondary Vocational Students. Journal of Vocational Education, (07): 38-9. 